Supplement of Weather Clim. Dynam., 1, 459-479, 2020

https://doi.org/10.5194/wcd-1-459-2020-supplement

Weather and

(C) Author(s) 2020. This work is distributed under

the Creative Commons Attribution 4.0 License.

(c) (1)

$\mathbf{L}$

Supplement of

\title{
The life cycle of upper-level troughs and ridges: a novel detection method, climatologies and Lagrangian characteristics
}

Sebastian Schemm et al.

Correspondence to: Sebastian Schemm (sebastian.schemm@env.ethz.ch)

The copyright of individual parts of the supplement might differ from the CC BY 4.0 License. 
Abstract. Supplementary figures:

- 300-hPa trough and ridge climatologies (Fig. 1 and Fig. 2).

- 500-hPa trough and ridge climatologies with short-lived features removed (Fig. 3).

- Climatologies of the mean trough lifetime at the 500-hPa level (Fig. 3). 


\section{Troughs}

(a) Nov-Mar

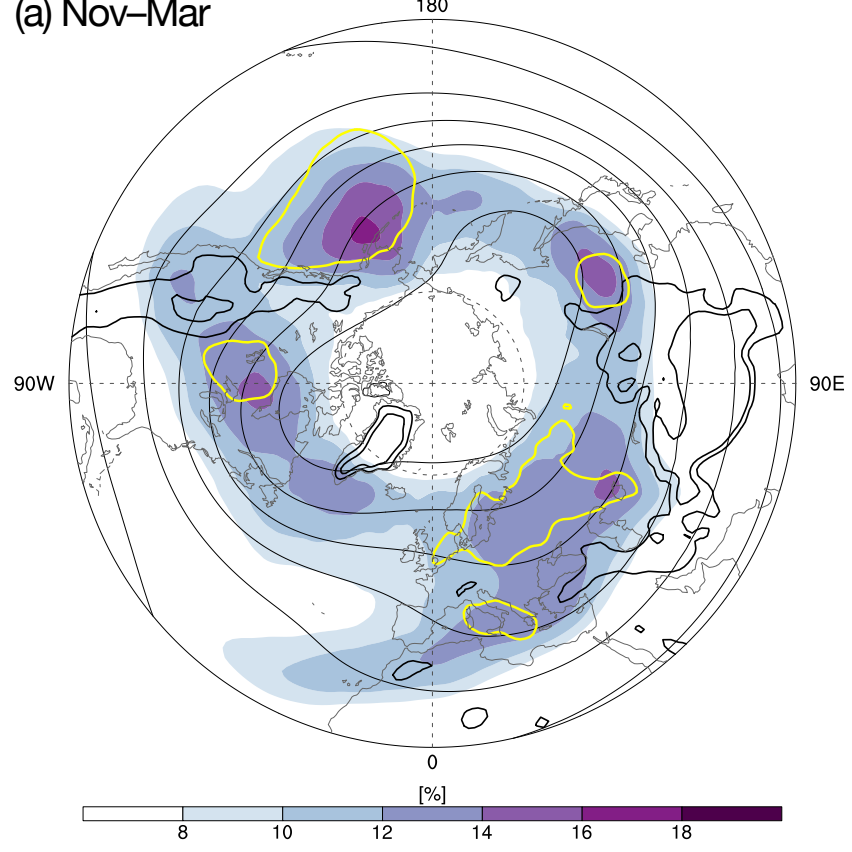

\section{(c) May-Sep}

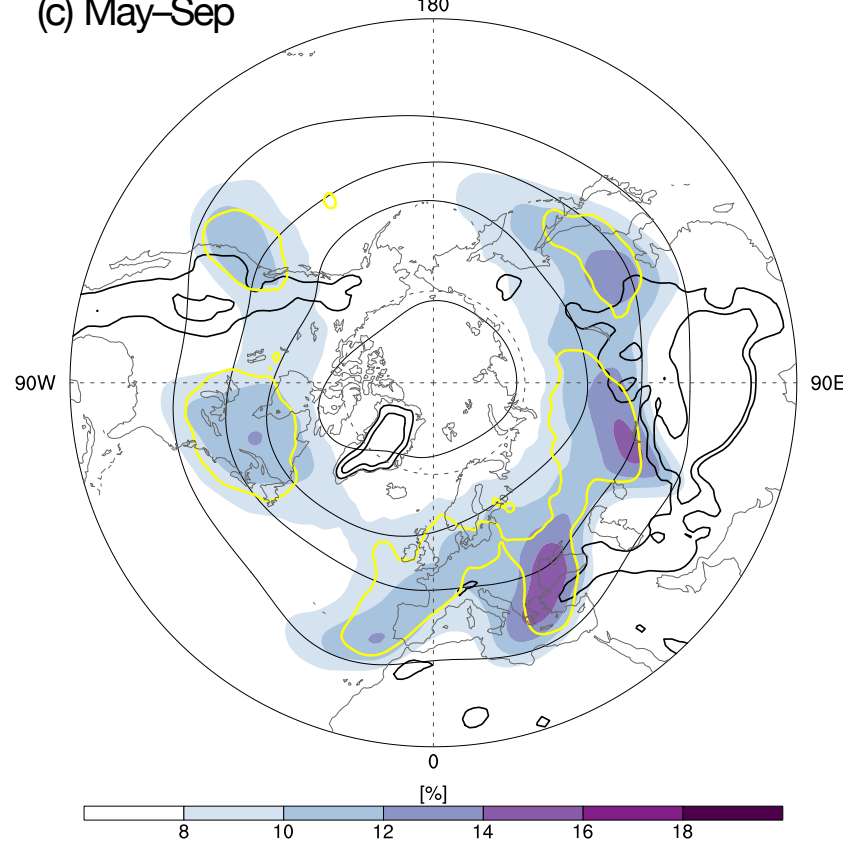

(b) Nov-Mar

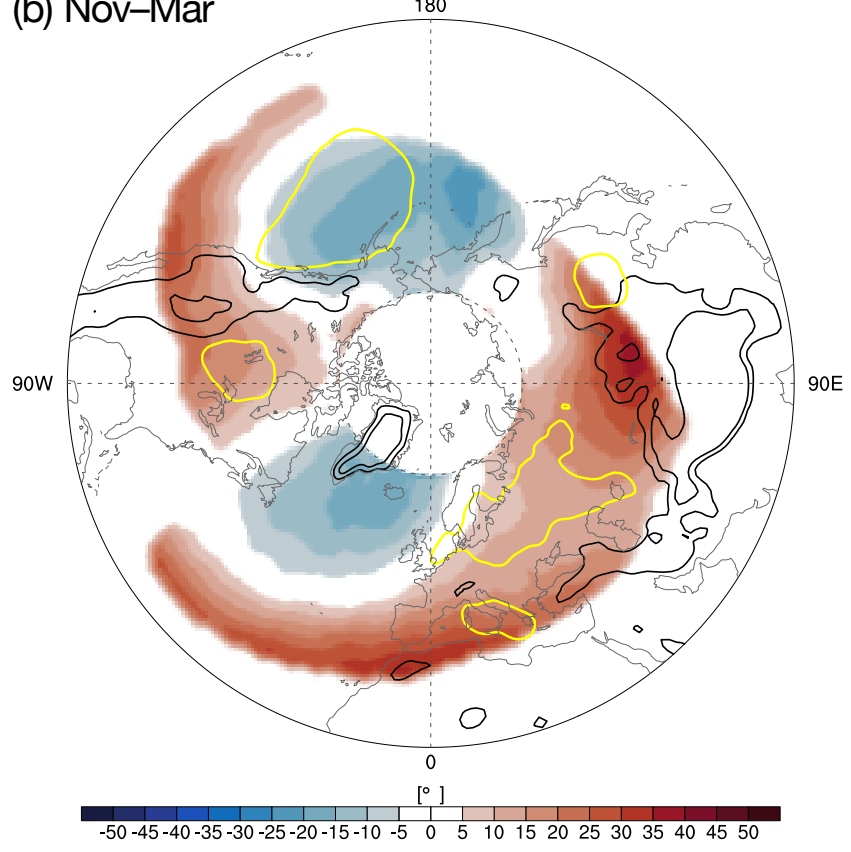

(d) May-Sep

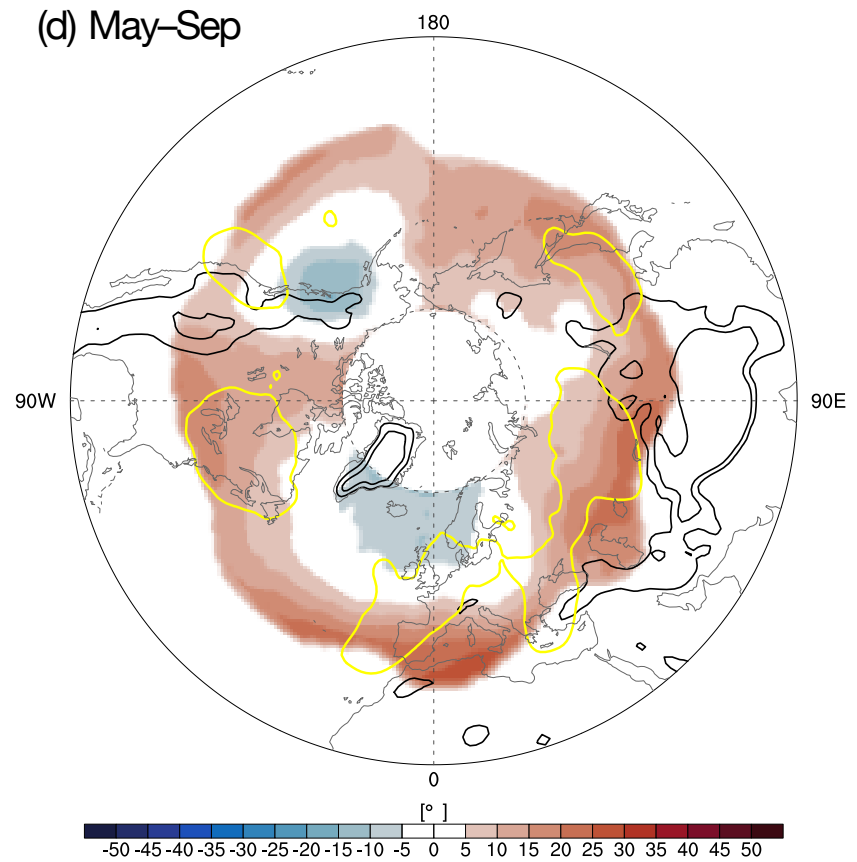

Figure 1. 300-hPa trough (left) detection frequencies and (right) corresponding horizontal orientation for the (a,b) cold (Nov-Mar) and (c,d) warm seasons (May-Sep). 


\section{Ridges}
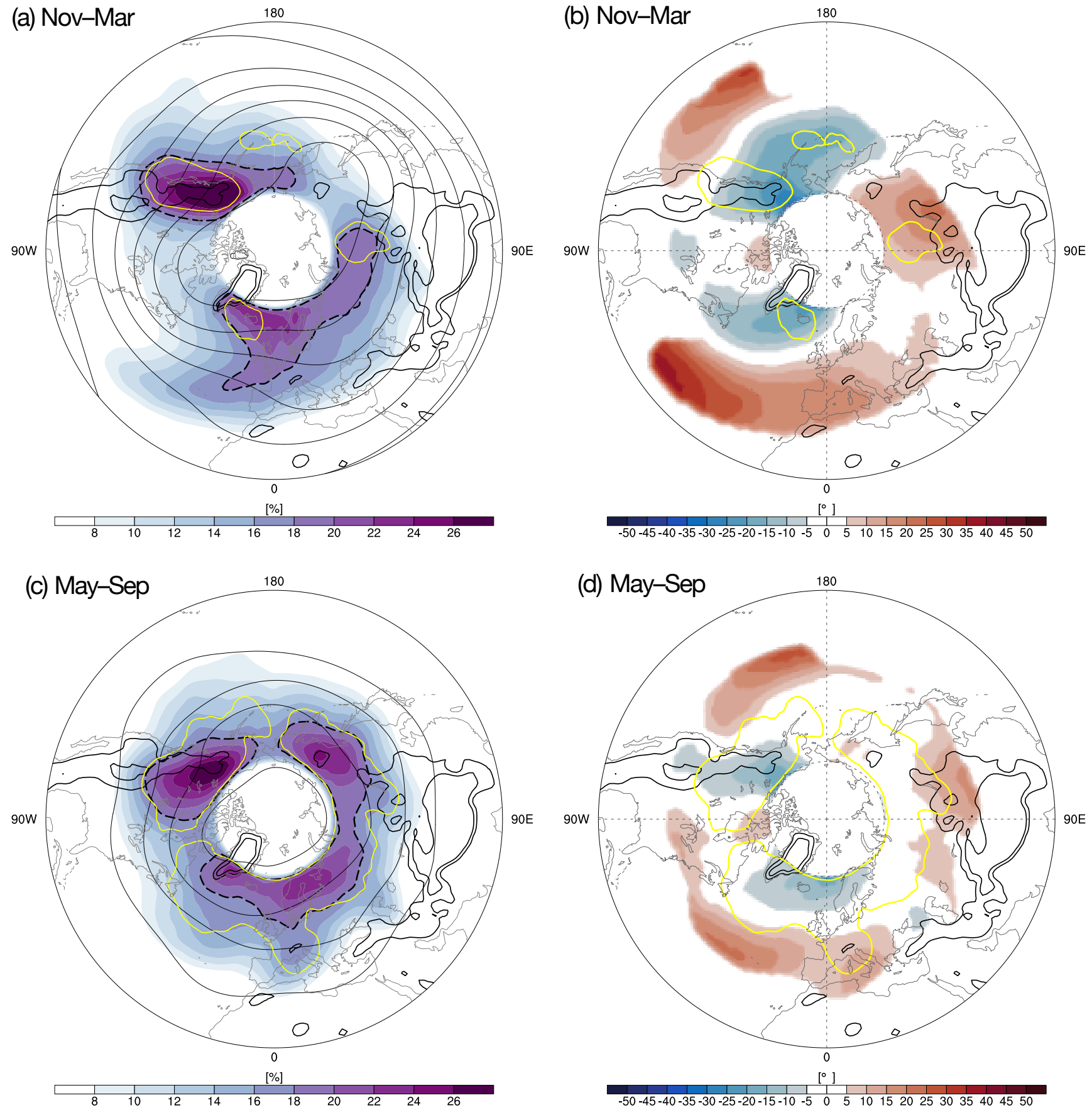

Figure 2. 300-hPa ridge (left) detection frequencies and (right) corresponding horizontal orientation for the (a,b) cold (Nov-Mar) and (c,d) warm seasons (May-Sep). 


\section{Troughs}

(a) Nov-Mar (Trough lifetime $>24$ hours)

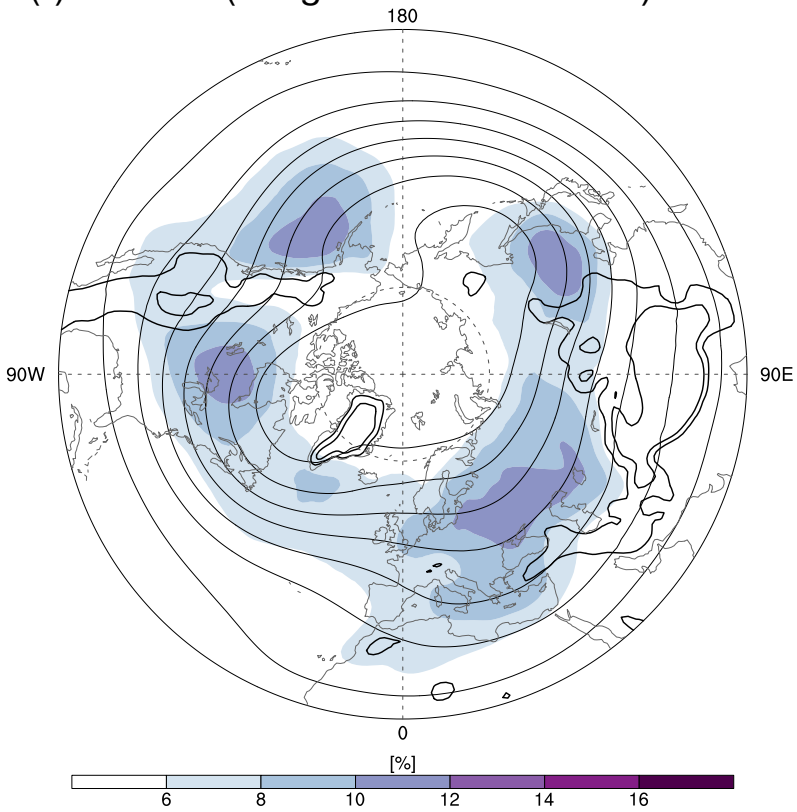

(c) May-Sep (Trough lifetime $>24$ hours)

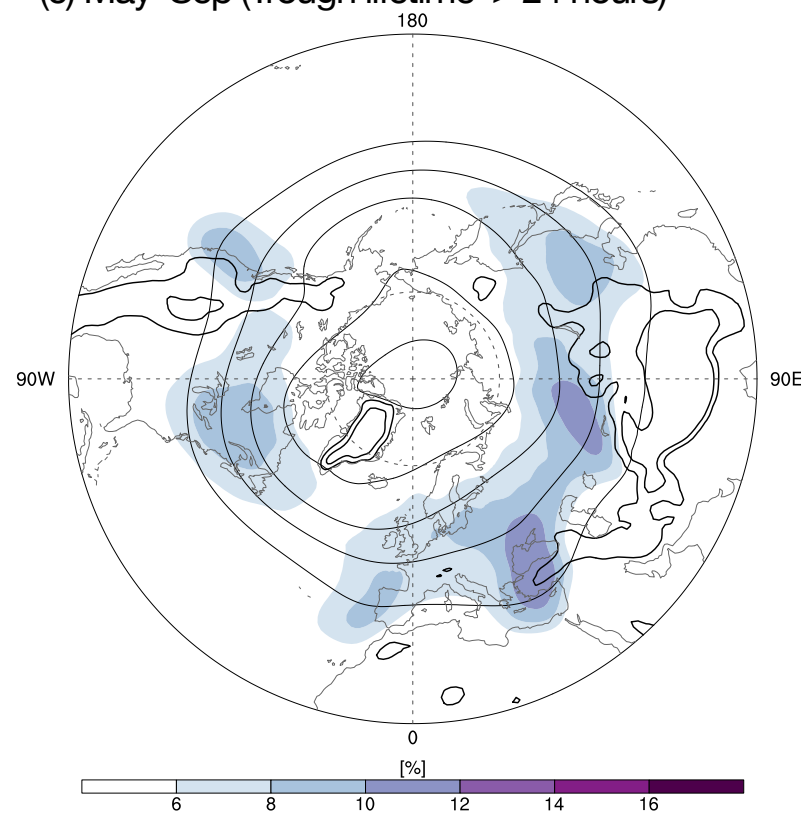

\section{Ridges}

(b) Nov-Mar (Ridge lifetime $>24$ hours)

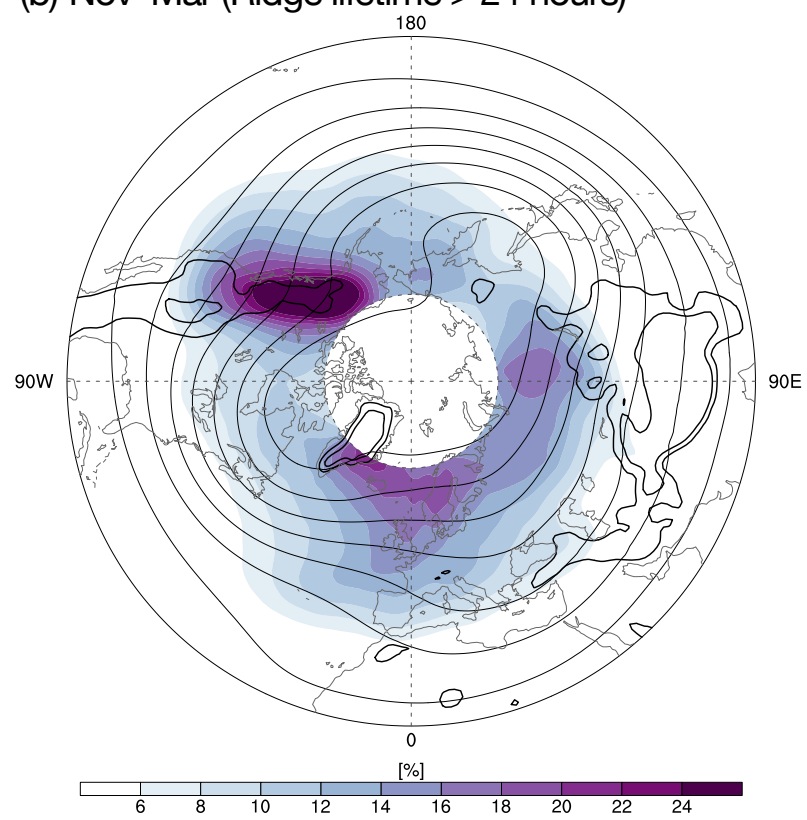

(d) May-Sep (Ridge lifetime $>24$ hours)

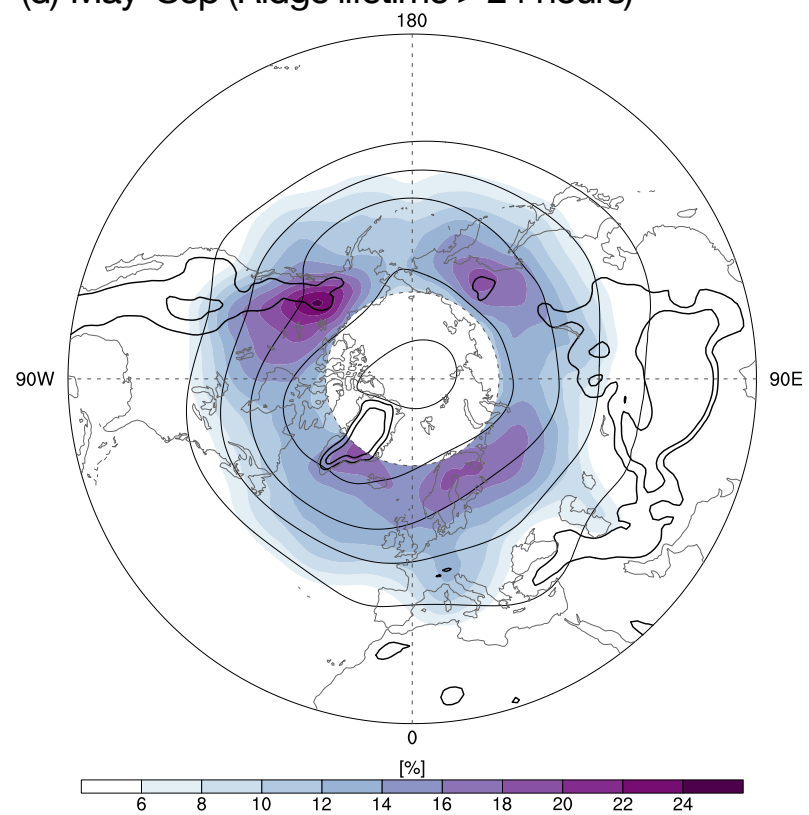

Figure 3. 500-hPa trough (left column) and ridge (right column) detection frequencies with short-lived features ( $<24$ hours) excluded. 
(a)

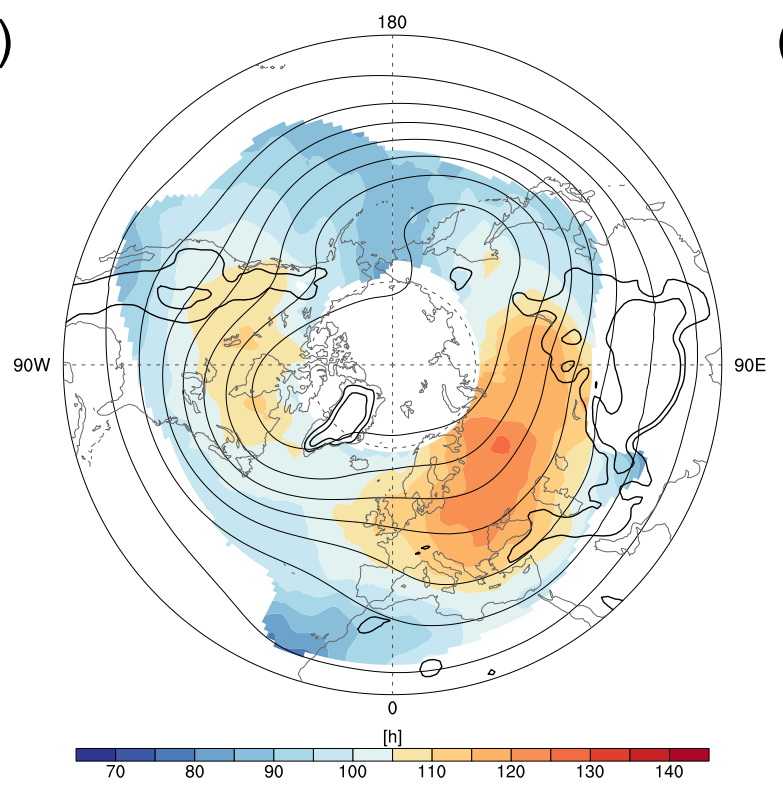

(b)

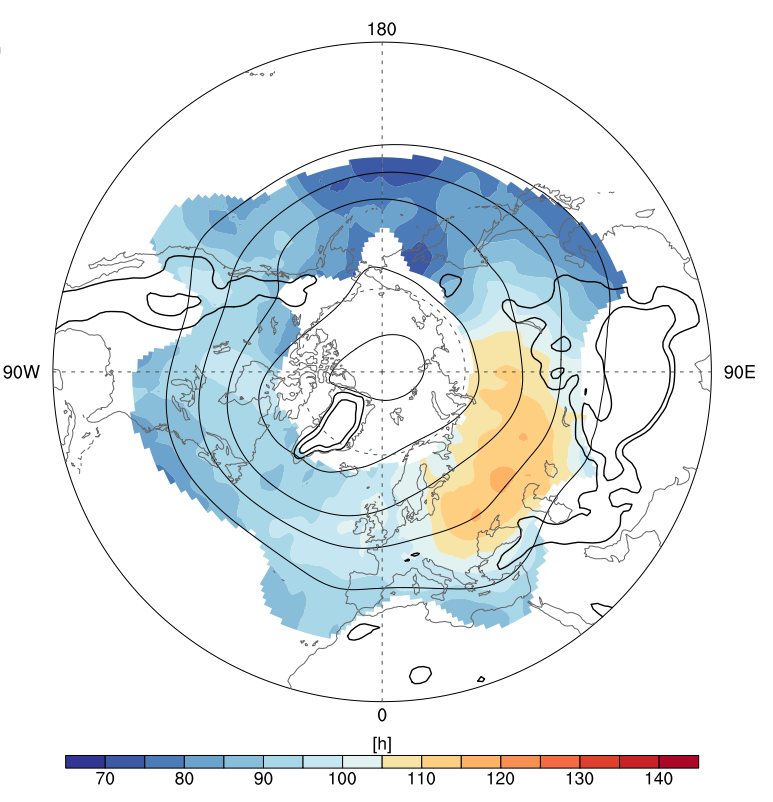

Figure 4. The mean trough lifetime during (a) the cold (Nov-Mar) and (b) warm season (May-Sep). 